\title{
Removal of hydrogen sulfide by zinc oxide nanoparticles in drilling fluid
}

\author{
${ }^{*}$ M. A. Sayyadnejad; H. R. Ghaffarian; M. Saeidi \\ Chemistry and Petrochemical Division, Research Institute of Petroleum Industry, Tehran, Iran \\ Received 7 May 2008; revised 26 June 2008; accepted 28 July 2008
}

\begin{abstract}
Hydrogen sulfide is a very dangerous, toxic and corrosive gas. It can diffuse into drilling fluid from formations during drilling of gas and oil wells. Hydrogen sulfide should be removed from this fluid to reduce the environmental pollution, protect the health of drilling workers and prevent corrosion of pipelines and equipments. In this research nano zinc oxide with 14-25 nm particle size and 44-56 $\mathrm{m}^{2} / \mathrm{g}$ specific surface area was synthesized by spray pyrolysis method. The synthesized nanoparticles were used to remove hydrogen sulfide from water based drilling fluid. The efficiency of these nanoparticles in the removal of hydrogen sulfide from drilling mud were evaluated and compared with that of bulk zinc oxide. The obtained results show that synthesized zinc oxide nanoparticles are completely able to remove hydrogen sulfide from water based drilling mud in just 15 min., whereas bulk zinc oxide is able to remove $2.5 \%$ of hydrogen sulfide in as long as 90 min. under the same operating conditions.
\end{abstract}

Key words: Nano zinc oxide, pollution, hydrogen suifide, scavenger, absorbent, acid gas

\section{INTRODUCTION}

Large quantities of hydrogen sulfide $\left(\mathrm{H}_{2} \mathrm{~S}\right)$ are produced in gas and petroleum industries. It is a corrosive (Duan et al.,2007; Perdomo et al.,2002; Ren et al.,2005) and highly toxic gas and it can be regarded as a major source of air pollution( Haimour et al.,2005). According to the international environmental regulations, $\mathrm{H}_{2} \mathrm{~S}$ contained in the acid gases should be effectively removed before emission to atmosphere.

$\mathrm{H}_{2} \mathrm{~S}$ diffused into the drilling fluid, is produced by Sulphate reducing bacteria (SRB) in sea water or in formation water (connate water) under anaerobic conditions where the SRB grow with organic materials such as crude oil as a substrate (Sandnes and Hundvag, 2002). Hydrogen sulfide is a colorless gas and low concentrations of it in air smell like rotten eggs. Its characteristic odor is perceptible in fresh air in a dilution of $0.002 \mathrm{mg} / \mathrm{L}$ of air. However the human sense of smell quickly becomes fatigued and may fail to give warning of higher concentration. Coma, collapse and death from respiratory failure may occur within a few seconds after one or two inspiration of the undiluted

\footnotetext{
\*Corresponding Author Email: sayyadnejadma@ripi.ir Tel.: +9821 5590 1021; Fax: +9821 55932428
}

gas (Ferguson, 1975). $\mathrm{H}_{2} \mathrm{~S}$ can be present in drilling $\mathrm{mud} /$ water either as $\mathrm{H}_{2} \mathrm{~S}, \mathrm{HS}^{-}$or $\mathrm{S}^{-2}$, depending on the $\mathrm{pH}$ value (Sandnes and Hundvag, 2002). To protect the health of drilling workers, the concentration of this gas should be reduced to less than 15 ppm (Davidson, 2004).

Various absorbents have been used in industry to remove $\mathrm{H}_{2} \mathrm{~S}$ form different media (Jung et al., 2006; Li and King, 2006; Ros et al., 2007). Zinc compounds such as zinc oxide $(\mathrm{ZnO})$ and zinc carbonate are common scavengers to remove $\mathrm{H}_{2} \mathrm{~S}$ from drilling fluids (Davidson, 2004). $\mathrm{ZnO}$ is a commodity sorbent and good candidate for the removal of $\mathrm{H}_{2} \mathrm{~S}$ in drilling fluids, because it has high zinc content (80\%) and has well predictable reaction kinetics and absorption capacity. It is also readily available compared with other sorbents, such as molecular sieves or zinc-titanium oxide. $\mathrm{H}_{2} \mathrm{~S}$ absorption by $\mathrm{ZnO}$ is actually controlled by the following reaction that forms inert insoluble zinc sulfide (Bagreev et al., 2001; Sun et al., 2007):

$$
\mathrm{ZnO}+\mathrm{H}_{2} \mathrm{~S} \rightarrow \mathrm{ZnS}+\mathrm{H}_{2} \mathrm{O}
$$

$\mathrm{ZnO}$ nanoparticles have large surface area and high 
surface activities. These important key characteristics provide a wide range of potential application in various industries (Hong et al., 2006; Lee et al., 2008; Wang et al., 2008). Spent $\mathrm{ZnO}$ sorbent is considered nonhazardous for solid waste disposal (Sun et al., 2007). ZnO nanoparticles are being used in personal care products and the toxicity of these and bulk $\mathrm{ZnO}$ has been investigated on fresh water microalga. The chronic toxicity of $\mathrm{ZnO}$ nanoparticles has been statistically similar to that of bulk ZnO (Frankline et al., 2007). Given the above findings, it was decided to investigate the performance of nano $\mathrm{ZnO}$ as a $\mathrm{H}_{2} \mathrm{~S}$ scavenger in drilling fluids.

\section{MATERIALS AND METHODS}

Bulk zinc oxide with purity of $99.5 \%$ was supplied from Pars company (Iran). Zinc oxide nanoparticles used in this work were synthesized by spray pyrolysis method (Ghaffarian et al., 2008; Okuyama and Lenggoro., 2003) and were characterized by x-ray diffraction (XRD, PW 1840, Phillips, Netherland), scanning electron microscope (SEM,S-360, Cambridge, England), atomic force microscope (AFM, P47H, NTMDT, Russia) and transmission electron microscope (TEM, AT-210, Bruker, Germany).

Three samples were synthesized with different surface areas and were designated Snano 1, Snano 2 and Snano 3. Fig. 1 illustrates the TEM image of Snano 1. The phase analysis of above samples were performed by XRD and identification of the phases were carried out by using International Center Diffraction Data (JCPDS 36-1451).The diameter of ZnO nanoparticles was calculated using Debye-Sherrer equation.The specific surface area (SSA) of the samples and bulk $\mathrm{ZnO}$ were measured by $\mathrm{N}_{2}$ adsorption method, using BET technique (Quantasorb Model LMFE-7, USA). The physical characterization of $\mathrm{ZnO}$ nanoparticles and bulk $\mathrm{ZnO}$ used in the experiments are summarized in Table 1. The amount of removed $\mathrm{H}_{2} \mathrm{~S}$ in drilling mud by nano $\mathrm{ZnO}$ was measured according to the following procedure at room temperature.

$125 \mathrm{~mL}$ water based drilling mud and $125 \mathrm{~mL}$ water were poured into a beaker. After adding $1.5 \mathrm{~g}$ sodium sulfide nonahydrate (equivalent of about $800 \mathrm{ppm}_{2} \mathrm{~S}$ ), the slurry was homogenized by stirring for $30 \mathrm{~min}$. 50 $\mathrm{mL}$ of this solution was then taken out, filtered and used as blank. $3.42 \mathrm{~g} \mathrm{ZnO}$ nanoparticles were added to the rest of slurry and stirring was continued. $50 \mathrm{~mL}$ aliquots of the slurry were taken out at intervals of 10 and $15 \mathrm{~min}$. and filtered. The amount of removed sulfide in blank and filtrates were measured using, a standard method (APHA, 1998).

The experiment was carried out for Snano 1, Snano 2, Snano 3 and bulk $\mathrm{ZnO}$ respectively. Since the

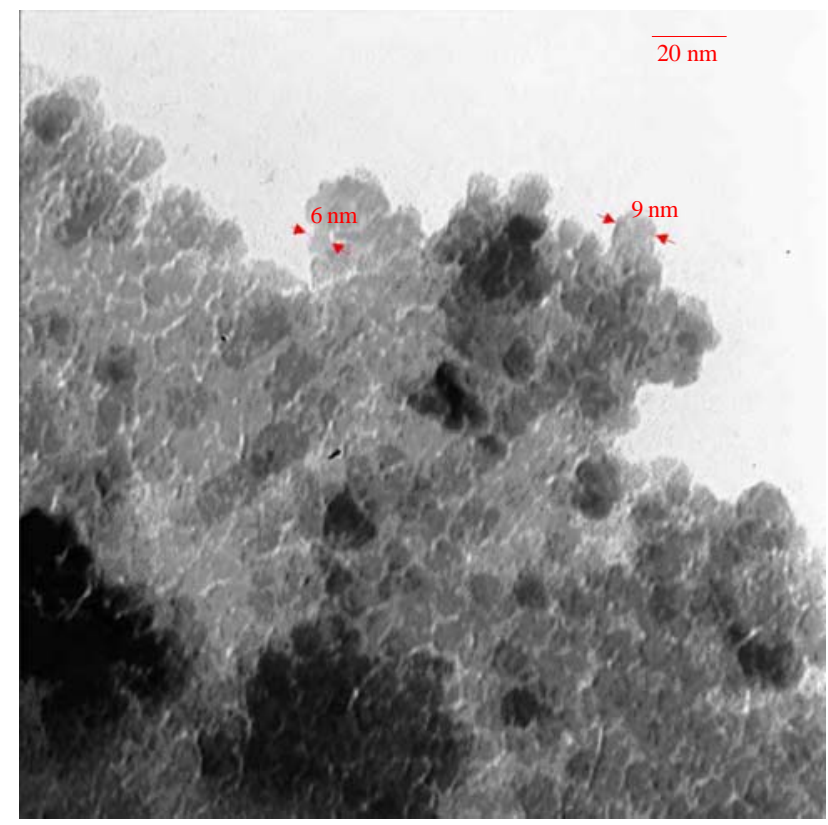

Fig. 1: TEM image of $\mathrm{ZnO}$ nanoparticles (Snano 1 sample) 
Int. J. Environ. Sci. Tech., 5 (4), 565-569, Autumn 2008

Table 1: Physical characterization of synthesized $\mathrm{ZnO}$ nanoparticles and bulk $\mathrm{ZnO}$

\begin{tabular}{llll}
\hline Sample & Crystal size $(\mathrm{nm})$ & SSA $(\mathrm{BET})\left(\mathrm{m}^{2} / \mathrm{g}\right)$ & Phase $($ XRD) \\
\hline Snano 1 & 15 & 51 & Wurtzite \\
Snano 2 & 25 & 44 & Wurtzite \\
Snano 3 & 14 & 56 & Wurtzite \\
Bulk ZnO & 243 & 5 & Wurtzite \\
\hline
\end{tabular}
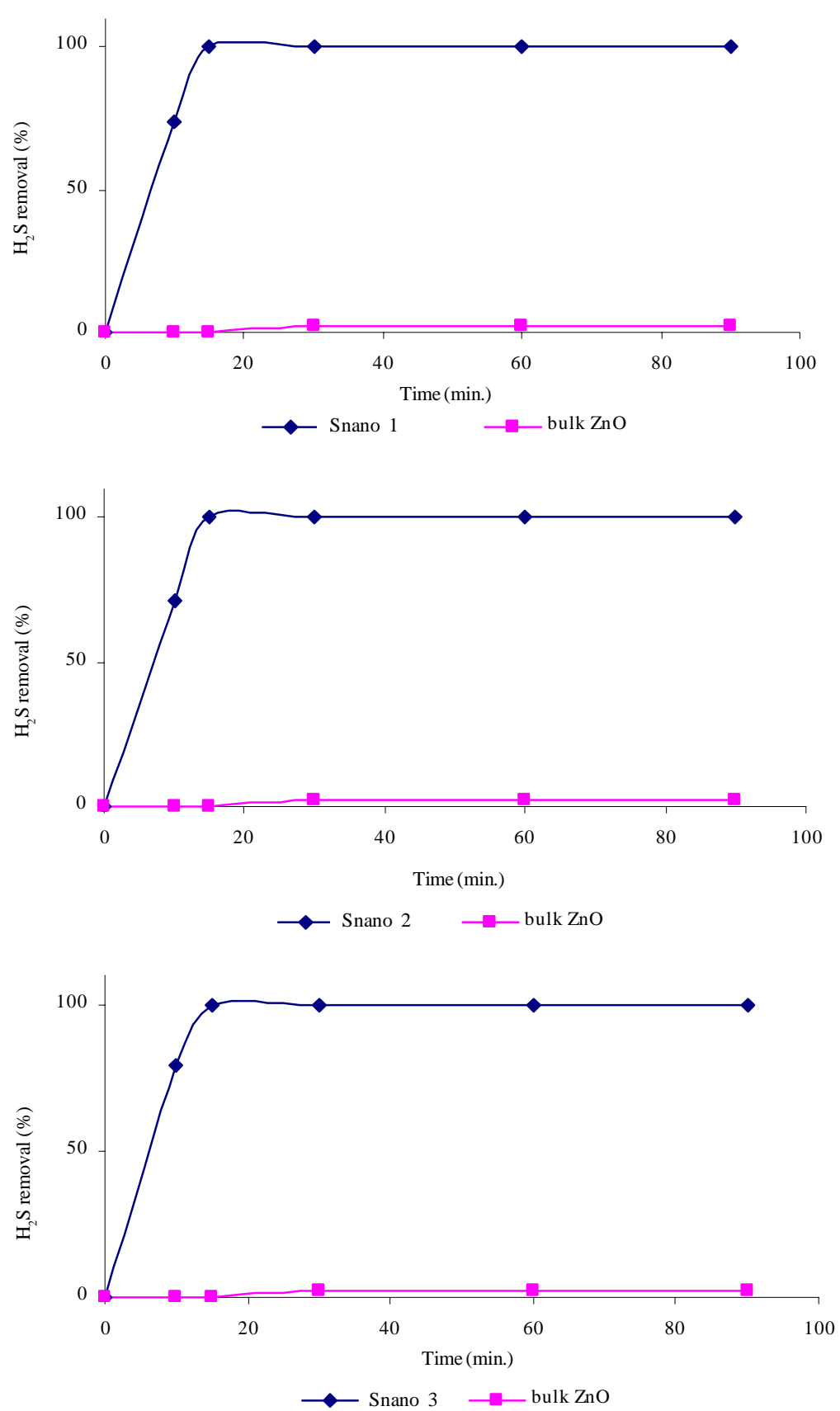

Fig. 2: comparison of $\mathrm{H}_{2} \mathrm{~S}$ amount removed by $\mathrm{ZnO}$ nanoparticles and bulk $\mathrm{ZnO}$ 
Removal of hydrogen sulfide by zinc oxide

Table 2: The percentage of scavenged $\mathrm{H}_{2} \mathrm{~S}$ by nano $\mathrm{ZnO}$ samples and bulk $\mathrm{ZnO}$

\begin{tabular}{|c|c|c|c|c|c|c|}
\hline Sample & Blank & 10 (min.) & 15 (min.) & 30 (min.) & 60 (min.) & 90 (min.) \\
\hline Snano 1 & 0 & 73.5 & 100 & - & - & - \\
\hline Snano 2 & 0 & 71.0 & 100 & - & - & - \\
\hline Snano 3 & 0 & 79.0 & 100 & - & - & - \\
\hline Bulk ZnO & 0 & _ & _ & 2.5 & 2.5 & 2.5 \\
\hline
\end{tabular}

absorption rate of bulk $\mathrm{ZnO}$ was low. The sampling was done in 30, 60 and 90 min. intervals, respectively.

\section{RESULTS AND DISSCOSION}

The amounts of scavenged $\mathrm{H}_{2} \mathrm{~S}$ by $\mathrm{ZnO}$ nanoparticles and bulk $\mathrm{ZnO}$ in water- base drilling mud is shown in Table 2. Investigation of Tables 1 and 2 indicates that, as the specific surface area of nanoparticles increases from 44 to $56 \mathrm{~m}^{2} / \mathrm{g}$, the amount of scavenged hydrogen sulfide increases from 71 to $79 \%$ after 10 min. All nano samples completely remove $\mathrm{H}_{2} \mathrm{~S}$ from mud after 15 min., whereas bulk $\mathrm{ZnO}$ removes $2.5 \%$ of $\mathrm{H}_{2} \mathrm{~S}$ in as long as $90 \mathrm{~min}$. The ability of $\mathrm{ZnO}$ nanoparticles in comparison with bulk $\mathrm{ZnO}$ to remove hydrogen sulfide in water- base drilling mud has been shown in Fig. 2.

As shown in Fig. 2, there is a remarkable difference between the rates of $\mathrm{H}_{2} \mathrm{~S}$ absorption on nanoparticles and bulk ZnO. According to Fig. 1, nanoparticles have a very high porosity, which results in their high surface area and pore volume, therefore; they can scavenge $\mathrm{H}_{2} \mathrm{~S}$ much faster than bulk $\mathrm{ZnO}$. Since $\mathrm{ZnO}$ has also been used as an effective scavenger for removing soluble sulfides from oil-based muds (Garrett et al., 1988), nano $\mathrm{ZnO}$ can also be used in such muds. The obtained results in this research show that, $\mathrm{ZnO}$ nanoparticles in the range of about $14-25 \mathrm{~nm}$ size are reliable scavengers to effectively remove $\mathrm{H}_{2} \mathrm{~S}$ and soluble sulfides from drilling fluids. Superior performance of nanoparticles in the elimination of $\mathrm{H}_{2} \mathrm{~S}$ will decrease consumption of bulk $\mathrm{ZnO}$, which will result in minimizing the environmental pollution and lower consumption of natural resources

\section{REFERENCES}

APHA, (1998). Standard methods for the examination of water and waste water, APHA.,AWWA.,WEF, 20 ${ }^{\text {th }}$.Ed., 4167.

Bagreev, A.; Bashkova, S.; Locke, D. C.; Bandosz, T. J., (2001). Sewage sludge-derived materials as efficient adsorbents for removal of hydrogen sulfide., Environ. Sci. Tech., 35 (7), 1537-1543.

Davidson, E., (2004). Method and composition for scavenging sulphid in drilling fluids., U.S. Patent: 6476611.

Duan, Z.; Sun, R.; Liu, R.; Zhu, C., (2007). Accurate thermodynamic model for the calculation of $\mathrm{H}_{2} \mathrm{~S}$ solubility in pure water and brines., Energ. Fuel., 21 (4), 2056-2065.

Ferguson, P. A., (1975). Hydrogen sulfide removal from gases, air, and liquids., Noyes Data coorporation, new Jersey, USA..

Franklin, N. M.; Rogers, N. J.; Apte, S. C.; Batley, G. E.; Gadd, G. E.; Casey, P. S., (2007). Comparative toxicity of nanoparticulate $\mathrm{ZnO}$, bulk $\mathrm{ZnO}$, and $\mathrm{ZnCl}_{2}$ to a fresh water microalga; Pseudokirchneriella subcapitata: The importance of particle solubility., Environ. Sci. Tech., 41 (24), 84848490.

Garrett, R. L.; Carlton, L. A.; Denekas, M. O., (1988). Methods for field monitoring of oil- based drilling fluids for hydrogen sulfide and water intrusions., SPE Drill. Eng., 3 (3), 296302 .

Ghaffarian, H. R.; Sayyadnejad, M. A.; Rashidi, A. M.; Saiedi, M.; Parhizkar, R., (2008). Preparation of zinc oxide nanoparticles by water solution combustion method., In IChEC, $5^{\text {th }}$ international chemical engineering congress 2-5 January , kish Island, I.R.Iran.

Haimour, N.; El-Bishtawi, R.; Ail-Wahbi, A., (2005). Equilibrium adsorption of hydrogen sulfide onto $\mathrm{CuO}$ and $\mathrm{ZnO}$., Desalination, 181 (1-3), 145-152.

Hong, R.; Pan, T.; Qian, J.; Li, H., (2006). Synthesis and surface modification of ZnO nanoparticles., Chem. Eng. J., 119 (2-3), 71-81.

Jung, S. Y.; Lee, S. J.; Lee, T. J.; Ryu, C. K.; Kim, J. C., (2006). $\mathrm{H}_{2} \mathrm{~S}$ removal and regeneration properties of Zn-Al-based sorbents promoted with various promoters., Catal. Today, 111 (3-4), 217-222.

Lee, Y. J.; Park, N.; Han, G. B. ; Ryu, S. O.; Lee, T. G.; Chang, C. H., (2008). The preparation and desulfurization of nanosize Zno by a matrix-assisted method for the removal of low concentration of sulfur compounds., Curr. Appl. Phys., 8 (6), 746-751.

Li, L.; king, D. L., (2006). H2S removal with ZnO during fuel processing for PEM fuel applications., Catal. Today, 116 (4), 537-541.

Okuyama, K.; Lenggoro, I. W., (2003). Preparation of nanoparticles via spray route., Chem. Eng. Sci., 58 (3-6), 537-547.

Perdomo, J. J. ; Morales, J. L.; Viloria, A.; Lusinchi, A. J., (2002). Carbon dioxide and hydrogen sulfide corrosion of API 5L grades B and X 52 steels., MP, 41 (3), 54-58. 
Ren, C.; Liu, D.; Bai, Z.; Li, T., (2005).Corrosion behavior of oil tube steel in simulant solution with hydrogen sulfide and carbon dioxide., Mater. Chem. phys., 93 (2-3), 305-309.

Ros, A.; Lillo-Rodenas, M. A.; Canals-Batlle, C.; Fuente, E.; Montes-Moran., M. A.; Martin, M. J.; Linares-Solano, A., (2007). A new generation sludge-based Adsorbent for $\mathrm{H}_{2} \mathrm{~S}$ abatement at room temperature., Environ. Sci. Tech., 41 (12), 4375-4381.

Sandnes, E. S.; Hundvag, H. O.,(2002). Removal of $\mathrm{H}_{2} \mathrm{~S}$ in drilling mud., U.S. Patent: 6365053 B1
Sun, J.; Modi, S.; Liu, K.; Lesieur, R.; Buglass, J., (2007). Kinetics of zinc oxide sulfidation for packed-bed desulfurizer modeling., Energ. Fuel., 21 (4), 1863-1871.

Wang, X.; Sun, T.; Yang, J.; Zhao, L.; Jia, J., (2008). Lowtemperature H2S removal from gas stream with SAB-15 supported ZnO nanoparticles., Chem. Eng. J., 142 (1), 4855.

\section{AUTHOR (S) BIOSKETCHES}

Sayyadnejad, M. A., M.Sc., research faculty, Chemistry and Petrochemical Division, Research Institute of Petroleum Industry (RIPI), Tehran, Iran. Email: sayyadnejadma@ripi.ir

Ghaffarian, H. R., M.Sc., research faculty, Chemistry and Petrochemical Division, Research Institute of Petroleum Industry (RIPI) , Tehran, Iran. Email: ghaffarianhr@ripi.ir

Saeidi, M., M.Sc, research faculty, Chemistry and Petrochemical Division, Research Institute of Petroleum Industry (RIPI) ,Tehran, Iran. Email: saeidim@ripi.ir

This article should be referenced as follows:

Sayyadnejad, M. A.; Ghaffarian, H. R.; Saeidi, M., (2008). Removal of hydrogen sulfide by zinc oxide nanoparticles in drilling fluid. Int. J. Environ. Sci. Tech., 5 (4), 565-569. 